\title{
REVISITING THE CURRENT UAV REGULATIONS IN NEPAL: A STEP TOWARDS LEGAL DIMENSION FOR UAVS EFFICIENT APPLICATION
}

\author{
R. Shrestha ${ }^{1}$ *, J. Zevenbergen ${ }^{2}$, U. S. Panday ${ }^{1}$, B. Awasthi ${ }^{1}$, S. Karki ${ }^{1}$ \\ ${ }^{1}$ Dept. of Geomatic Engineering, Kathmandu University, 45200 Dhulikhel, Nepal - (reshma, uspanday, basant.awasthi, \\ shashank.karki)@ ku.edu.np \\ ${ }^{2}$ Department of Urban and Regional Planning and Geo-information management, Faculty of Geo-information Science and Earth \\ Observation, University of Twente, Hengelosestraat 997514 AE Enschede, Netherlands - \\ j.a.zevenbergen@utwente.nl
}

\section{Commission V, WG V/7 \& Commission IV, WG IV/6}

KEY WORDS: UAVs, Regulations, Geospatial Technology

\begin{abstract}
:
UAVs-Unmanned Aerial Vehicles- also known as drones, are an emerging geospatial technology that can facilitate data acquisition at various temporal and spatial scales. Notwithstanding, the wide application of UAVs globally, its wider application is found to be growing in Nepal as well. For instance, precision agriculture, forestry, topographical surveying, etc. It seems that there is a correlation between efficient use of UAVs in these sectors and the legal frameworks that regulate the use of UAVs. Therefore, it seems necessary to obtain holistic national view of UAVs regulations. Aligning with this necessity, this paper provides insight on existing legal provisions for UAVs in Nepal by highlighting the importance, impact, and limitations of UAV regulations. The criteria used in the framework to capture the present holistic legal dimension from literature in the web of science database are a) applicability b) technical requirements c) operational requirements/ limitations d) administration procedure e) human resource requirements and f) implementation of ethical constraints. The adopted methodological approach consists of exploratory case studies, systematic reviews of the concerned literature on UAVs regulations and the workshop on "Flight 4 Purpose" in which various UAVs application were discussed. The results show that the existing legal framework has both strengths and weaknesses for its use to capture the spatial data. The way forward is to harmonize the soft and hard regulations so that such geospatial technology can be applied for overall development and ultimately for the societal benefits.
\end{abstract}

\section{INTRODUCTION}

\subsection{UAVs}

Unmanned Aerial Vehicles (UAVs) also known as drones (Floreano \& Wood, 2015), remotely piloted craft (MuleroPázmány et al., 2014), Unmanned Aerial System (UAS) (Puliti et al., 2015) refer to aircraft which fly without a human operator on-board. Despite of various terminology applied, this study has adopted the term UAV and Drone.

The UAV can be classified on the basis of aerial platforms. Mostly, there are four different types of UAVs, namely MultiRotor Drones, Fixed Wing Drones, Single Rotor Helicopter and Fixed Wing Hybrid Vertical Take-off and Landing (VTOL). These UAVs are used in accordance with purpose and accuracy of the work (Dalamagkidis, 2015).

Multirotor drones are the most common types of drones typically used in aerial photography, topographic mapping, 3D models aerial video surveillance, and so on. Whereas Fixedwing drones are different in design and cannot hover like multirotor drones. It is mostly used in photogrammetric mapping and crop health monitoring. Looking to Single rotor drones, it resembles actual helicopters. Fixed Wing Hybrid VTOL are hybrid versions combining the benefits of Fixed- wing models (higher flying time) with that of rotor based models (Liu \& Chen, 2018)

The basic components of drones are remote controller, propeller, battery, GPS, landing gear, antenna, sensors, and display unit. The component's size, model and usage vary with the types of drones.

\subsection{Application of UAVs}

Briefly exploring the UAVs development history, it is found that firstly it was applied in military applications. Later the use of this technology has been expanded in other sectors. For instance, in 1986, the application of UAVs were tested for monitoring forest fires later on its application was found in weather forecasting, mineral exploration, coastal management, wildlife census and its tracking, forestry \& agriculture (Raparelli \& Bajocco, 2019), construction safety (Gheisari \& Esmaeili, 2019), surveying and route planning (Desa et al., 2019). Notwithstanding its application on the technical aspect, its effective application has been seen in the humanitarian response (Meier, 2015). This initiative has highlighted very important application of the UAVs. Further, there is ongoing research on its applicability in obtaining land rights, land tenure security and in cadastre sector (Ramadhani et al., 2018; Stöcker et al., 2019a; Stöcker et al., 2019b). It seems that the

\footnotetext{
* Corresponding author
} 
use of such a technology can be a boom towards good urban land governance.

Despite recent improvements in technological and operational capabilities related to UAVs, there exist challenges for UAVs operators as well as end-users including aviation authorities. The challenges are basically linked with having the effective and efficient legal framework that defines "Go", "No Go", "How to Go?", "When to go?" and "Where to Go?." (Stöcker et al., 2017). This raises the need to establish the UAVs regulatory framework that supports the smooth application in various disciplines.

\subsection{The focus of the study}

After understanding viable technical opportunities that UAVs can provide in social, economic, environmental management and governance aspect, the focus of this study is to obtain holistic national view of UAVs regulations in Nepal. This paper provides insight into existing legal provisions for UAVs in Nepal by adopting the existing framework developed by Stöcker et al. (2017). The criteria adopted in the framework varies from operational to administrative aspect including governance aspect like ethics. The single case on the use of UAVs in the humanitarian response is studied to explore how the flight procedure is regulated in Nepal. Since, the case was from 2015, to capture the present context on the UAVs regulation of Nepal, the content analysis of the government documents, blogs and more explicitly the data obtained from the workshop namely "Flight 4 Purpose" have been considered.

The following sections consist of methodological/analytical framework that guides this study. Section 3 provides the methods applied to collect data. Section 4 describes analysis and discussion and finally Section 5 highlights recommendations based on importance, impact, and limitations and way forward for improvement in legal framework which is further followed by concluding remarks

\section{METHODOLOGICAL/ ANALYTICAL FRAMEWORK}

Based on Stöcker et al. (2017), the methodological framework to analyze the current Nepalese regulations on UVAs has been developed.

The criteria used in the framework to capture the present holistic legal dimension are a) applicability b) technical requirements c) operational limitations d) administration procedure e) human resource requirements and $f$ ) implementation of ethical constraints. The factors under the criteria are slightly modified by author baed on characteristic of data.

\subsection{Applicability of regulations}

The criteria refer to the scope of UAV regulation. Under this criterion, one of the factors to evaluate applicability is 'regulations that regulate the use of UAV based on the purpose'. Research, development work, fun, and recreational activities are a few examples of purpose. Similarly, weight of $\mathrm{UAV}$ and UAV flight permission based on land use type are other two criteria included in the framework to analyze applicability of UAV.

\subsection{Technical Requirements}

The criteria refer to essential instruments that are mandated for use of UAVs for spatial data collection. The regulations that regulate risk associated with UAVs flight by specifying riskminimizing equipment is one of the factors under technical requirements criteria. The examples are instruments like parachutes, other special fail-safe instruments. Similarly, specific technical requirements like material of the blades, GNSS device, instruments attached to avoid collision of UAVs during a flight that is operated in Beyond Visual Line Of Sight (BVLOS).

\subsection{Operational Limitations}

The criteria refer to the UAV's regulations that regulate and monitor the restriction of UAV flight in certain scenarios. The regulation like "No Fly Zones" based on the horizontal distance: for example, restrictions to distance from airports/airstrips, army camps, distance from people beyond UAV Pilot control, private property, army camps, jails, industrial buildings, nuclear power plants, hospitals, securitysensitive government buildings etc. is one of the factors for evaluating regulations over operational limits. Similarly, flight restrictions based on the flight height above ground and horizontal distance based on Visual Line Of Sight (VLOS), Extended Visual Line Of Sight (EVLOS) and Beyond Visual Line Of Sight (BVLOS) and are also the relevant factors that explain operational restrictions.

\subsection{Administrative Procedure}

The criterion refers to whether current regulations govern application procedure, operational certificate, need for registration, and need for insurance or not. Therefore, the factors included with this criterion are registration of platform, UAVs devices, flight approval from various sectors like National, Local, Police, landowner etc., compulsion of insurance policy to cover any harm/ damage by fight operation.

\subsection{Human resource requirements}

The criterion refers to either the current regulations govern the qualification of pilots and license to operate UAVs. In this criterion technical skills/ qualification of UAV Pilots like practical training, theoretical Knowledge, medical test, aeronautical test are the factors.

\subsection{Ethical constraints}

This criterion is one of the good governance components of UAV operation. It refers to the regulations that protect the use of information captured from UAVs. Within this criterion, data protection, privacy, data sharing policy are considered.

Table 1 shows the analytical/ methodological framework compiled from sections: $2.1,2.2,2.3,2.4,2.5,2.6$. 


\begin{tabular}{|l|l|}
\hline Criteria & Factors \\
\hline Applicability & $\begin{array}{l}\text { Regulations according to purpose, Regulations based } \\
\text { upon the weight of UAVs, Regulations based on the } \\
\text { characteristic of the site for flight (Area, Land Use } \\
\text { Types etc.) }\end{array}$ \\
\hline $\begin{array}{l}\text { Technical } \\
\text { Requirements }\end{array}$ & $\begin{array}{l}\text { Requirements to include instruments like parachutes, } \\
\text { other special failure and safety instruments, Specific } \\
\text { technical requirements like the material of the blades, } \\
\text { GNSS device, Instruments to avoid collision path that } \\
\text { is operated (BVLOS, BVLOS, and EVLOS) }\end{array}$ \\
\hline $\begin{array}{l}\text { Operational } \\
\text { Limitations }\end{array}$ & $\begin{array}{l}\text { No Fly zones Based on the horizontal distance : For } \\
\text { e.g. restrictions to distance from airports/airstrips, army } \\
\text { camps, distance from people, property, military areas, } \\
\text { jails, industrial buildings, nuclear power plants, } \\
\text { hospitals, government buildings, etc.), Flight } \\
\text { Restriction based on the Vertical Height, Horizontal } \\
\text { Distance based on VLOS, BVLOS, and EVLOS }\end{array}$ \\
\hline $\begin{array}{l}\text { Administrative } \\
\text { Procedure }\end{array}$ & $\begin{array}{l}\text { Registration of Platform, UAVs devices, Flight } \\
\text { approval, Insurance policy }\end{array}$ \\
\hline $\begin{array}{l}\text { Human } \\
\text { Resource } \\
\text { Requirement }\end{array}$ & $\begin{array}{l}\text { Technical skills/ Qualification of UAVs Pilots: } \\
\text { Practical training, theoretical Knowledge, medical test, } \\
\text { aeronautical test }\end{array}$ \\
\hline $\begin{array}{l}\text { Ethical } \\
\text { constraints }\end{array}$ & Data Protection, privacy, data sharing policy \\
\hline
\end{tabular}

Table 1. Analytical Framework based on (Stöcker et al., 2017) and modified by authors

\section{METHODS AND DATA ON UAV LEGAL REGULATIONS}

In this paper, the authors have applied case studies approach for data collection. The case studies design can be formulated as single-case and multiple-case design. The single exploratory case study approach is selected to collect data. Although Yin (2003) made a preference to make a choice of multiple cases as analytic conclusions derived from multiple case studies will be more powerful than one derived from single case study, the later one is selected. However, to overcome the weakness of a single case study approach, the workshop approach as one of the data collection approaches (Ørngreen \& Levinsen, 2017) has been adopted.

\subsection{Exploratory Case studies on UAVs Application on Humanitarian response after 2015 Nepal Earthquake}

After massive earthquake in Nepal $\left(25^{\text {th }}\right.$ April and $12^{\text {th }}$ May in 2015), various humanitarian activities had been conducted in the early response and recovery stages. The deployment of UAVs to capture aerial images in order to plan humanitarian activities is one of the very effective actions taken in those periods. See Figure 1.

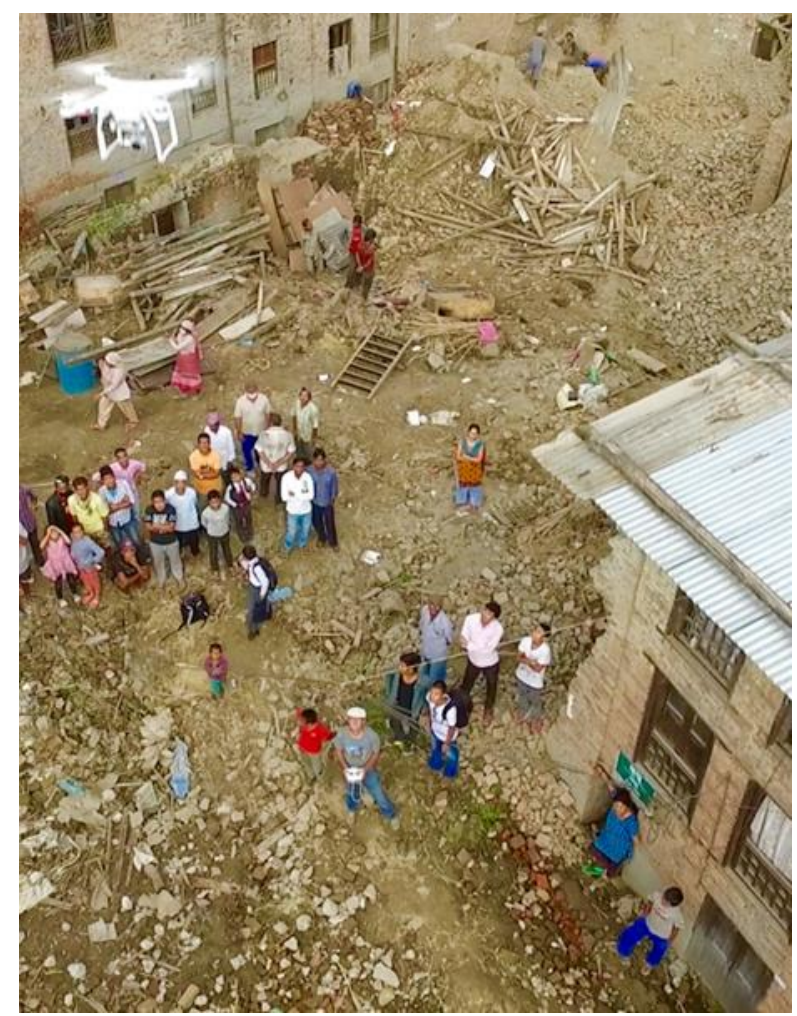

Figure 1. UAV flight to capture Aerial image of Panga (Meier, 2015)

UAViators in close collaboration with Kathmandu University (KU), KLL, DJI, and Pix4D had initiated their mission on the application of UAVs for early recovery responses. Besides hands-on training for capacity development on UAVs application, the team had carried out participatory mapping activities in one of the severely affected areas known as Panga, located in the Kirtipur Municipality (Meier, 2015). Using Phantom 3 Advanced quadcopters and Pix4Dmapper, orthomosaics were produced for the community to use in the reconstruction process and disaster preparedness (PIX4D, 2016). Error! Reference source not found. and Error! Reference source not found., the UAVs application on the recovery stages in which the local community was involved I identifying the buildings types and its damaged status, which seemed to be a very effective process for the informed decision making to avoid further human casualties and loss. This case has been studied considering legal regulations and its execution during the process of UAVs flight deployment and capturing images for the humanitarian responses. 


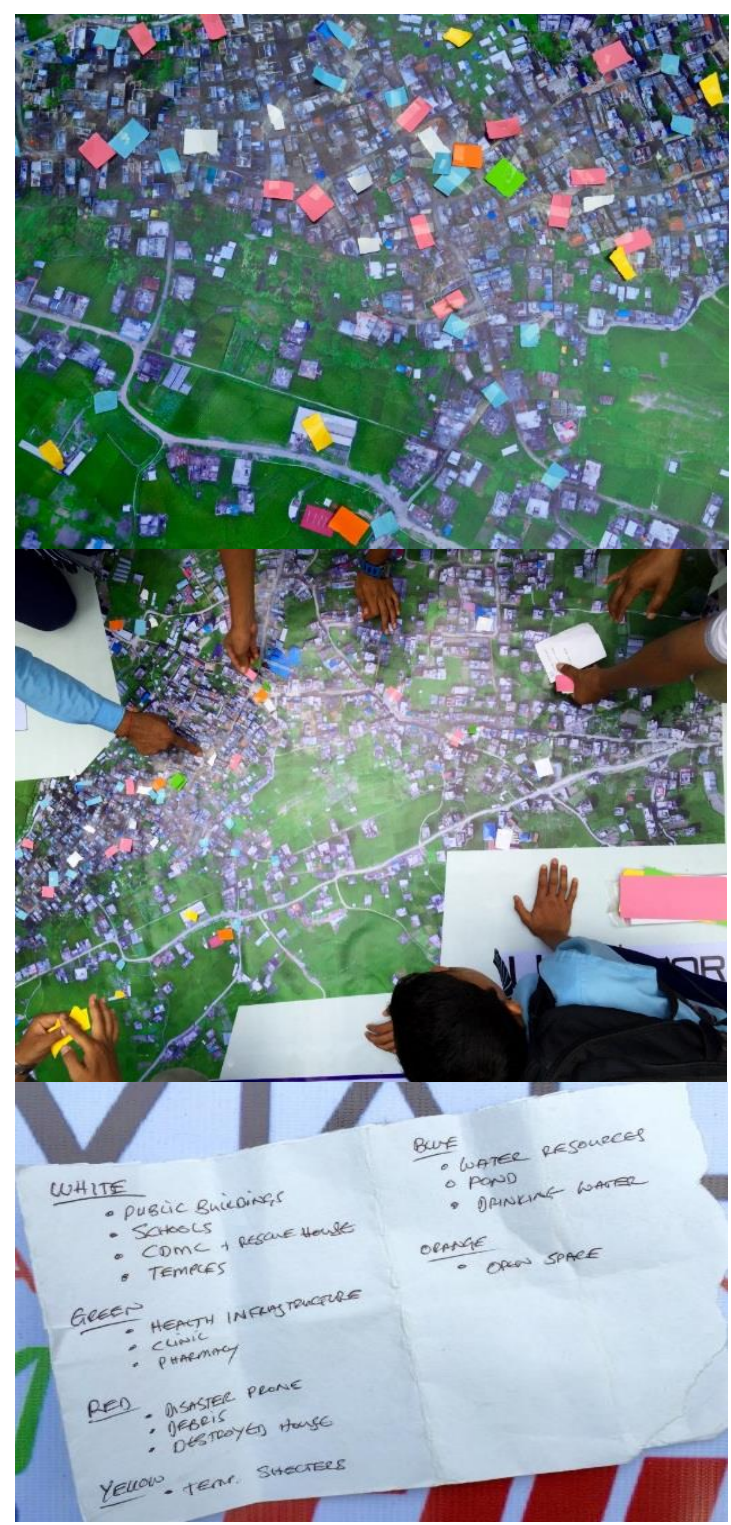

Figure 2. Participatory Mapping on Rapid Building Damage Assessment and buildings types (Source: (Meier, 2015)

\subsection{Workshop as a means for data collection}

An interactive workshop on "Flight 4 Purpose: Combating land tenure insecurity in Nepal's remote and vulnerable areas using UAVs" was conducted at Kathmandu University jointly by the Department of Geomatics Engineering and Kadastre International. In the workshop, there were presentations and discussion related to UAVs application and existing regulations that govern the use of UAVs for the surveillance and capturing spatial data/ images (Department of Geomatics Engineering, 2019; Dijkstra et al., 2019)

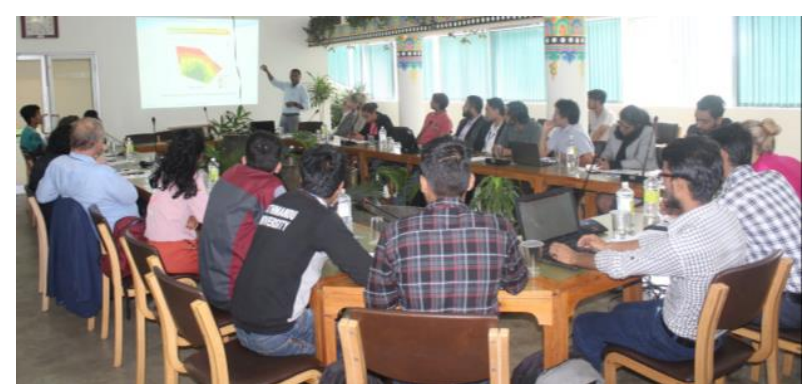

Figure 3. Workshop on Fit 4 Purpose (Department of Geomatics Engineering, 2019)

\subsection{Data on the UAVs Legal Regulations}

In this section, data on the existing UAV regulations have been presented which was collected based on the above-mentioned case studies, workshop and government documents on UAVs regulations: The content analysis (Mayring, 2004) approach has been adopted by considering the following government documents related to UAVs regulations.

$\checkmark$ Flight Operations Directive No. 7, May 2015' of Civil Aviation Authority of Nepal (Civil Aviation Authority of Nepal, 2015)

$\checkmark$ Remotely piloted aircraft (RPA) popularly known as 'DRONE' flight Act, 2019 (Ministry of Home Affairs, 2019)

\subsubsection{Applicability of UAVs :}

a) Regulations based upon the weight of UAVs:

The DJI Phantom 3 Advanced quadcopters were used. The weight of the UAVs is $1.28 \mathrm{KG}$. According to (Civil Aviation Authority of Nepal, 2015), the (drone) weighing less than $2 \mathrm{~kg}$ do not require permission from Civil Aviation Authority of Nepal (CAAN) while operating within the premises of the private property of the operator below $200 \mathrm{ft}$. above ground level (AGL)

The "Maximum Take-off Weight" (MTW) has been considered as a base for the categorization of UAVs and are categorized as follows.

\begin{tabular}{|l|l|l|l|l|}
\hline Category & A & B & C & D \\
\hline Weights & $<250$ gm & 250 gm-2 kg & $\begin{array}{l}>2 \text { kg- 25 } \\
\text { kg }\end{array}$ & $>25 \mathrm{Kg}$ \\
\hline Operations & $\begin{array}{l}\text { Very low } \\
\text { risk }\end{array}$ & Low Risk & $\begin{array}{l}\text { Regulated, } \\
\text { low risk }\end{array}$ & $\begin{array}{l}\text { Regulated, } \\
\text { high risk }\end{array}$ \\
\hline Examples & $\begin{array}{l}\text { Toy } \\
\text { UAV/drones }\end{array}$ & $\begin{array}{l}\text { DJI Phantom } \\
\text { 4 Pro, Mavic } \\
\text { 2 Pro }\end{array}$ & $\begin{array}{l}\text { DJI } \\
\text { Matrice } \\
\text { series, DJI } \\
\text { Inspire } \\
\text { Series }\end{array}$ & $\begin{array}{l}\text { Industrial } \\
\text { drones } \\
\text { with } \\
\text { payloads }\end{array}$ \\
\hline
\end{tabular}

Table 2. Categorization of UAV based on MTW

b) Regulations based on the characteristic of a site for flight (Area, Land Use Types, etc): 
The binding rules of restriction area were not applied in the above-mentioned case and there were no such regulations to govern the specific restriction area in the Flight operation directives 2015. However, the clauses 4.5 and 4.6 of the directives mentioned about the permission required from the concerned authority. The application of UAVs being applied for disaster relief activities, the local community such as the Community Disaster Management Committee (CDMC) of Panga was mobilized including the local people for the flight.

Later, the regulations by the Ministry of Home Affairs (2019) endorsed the risk-sensitive land use. The categorization as per the risk-sensitive land-use area where the flight is permitted are as follows:

$\checkmark$ General: Non-settlement area, open space not included prohibited/ preserved area

$\checkmark$ Medium: settlement, community, protected/ preserved area

$\checkmark$ Sensitive: Government offices, hospital, religious, cultural, archaeological, airport strips, air space, close to airport, Military and security offices

c) Regulations according to purpose:

The UAVs flight was planned to capture images for disaster management purposes. In 2015, when the use of UAVs was a recent development, the need for the society for the early recovery seems to overrule the formal regulations to some extent. Moreover, the flight operation directives 2015 is silent regarding purpose.

Whereas under the Drone Related Flight Work Plan 2019 (Ministry of Home Affairs, 2019), the purpose of the flight has been categorized as

Research, disaster management, service, and development oriented project/program, culture/religious/recreational/tourism, general communication, military/security

\subsubsection{Regulation followed under the Technical Requirements:}

a) Requirements to include special failure and safety instruments

The case reveals that UAV was not equipped with any special safety instruments like Parachute. There were no such binding regulations regarding requirements to include the technical failure security instruments (Civil Aviation Authority of Nepal, 2015). as the application of UAVs is the recent development. The flight was operated in autonomous mode however, the flight paths were limited within VLOS.

b)Specific technical requirements GNSS device, blade material

The regulations of the Civil Aviation Authority of Nepal (2015) do not seem to bind the risk-minimizing technical factor. Besides, it is mentioned that UAV flight operators should be aware of the harm to others. In this case, the UAV's propeller was made of plastic.

The present regulation by the Ministry of Home Affairs (2019) specified about restriction to items that are risky such as explosive items, weapons, and nuclear weapons, transfer of animal and person via UAV.

c)Instruments to avoid collision (VLOS, BVLOS, and EVLOS)

The regulations do not explicitly mention incorporating technical instruments. The flight is allowed within VLOS only. Only the restriction on the frequency for flying without interfering the telecommunication and security is mentioned.

\subsubsection{Regulations for the Operational Requirements and restrictions:}

a) No Fly zones Based on horizontal distance:

During the emergency situation of disaster management, the case reveals that there was no such restriction to be taken into account seriously. There were no binding rules such as "No Fly Zones" is mentioned in the flight operation directives except it is mentioned that "if the operations need to be conducted in a Restricted or Prohibited area, approval from the concerned authority is required before applying to CAAN for flight permission". The flight plan was scheduled for Panga. The area does not consist of flight sensitive zones like within buffer zone to airport, high-level government agencies, army camps, jails. Moreover, Civil Aviation Authority of Nepal (2015) does not mention the risk area very clearly.

The regulations endorsed by Ministry of Home Affairs (2019) have clearly demarcated the "No-fly Zone" above the personal property (land, house), public space, religious, cultural, archaeology, $5 \mathrm{~km}$ horizontal distance from international boundary, $1 \mathrm{~km}$ aerial distance from sensitive area/ security offices, $5 \mathrm{~km}$ around airport area, $1000 \mathrm{~m}$ aerial distance from special religious, high level government offices, president/ prime minister residence, $1000 \mathrm{~m}$ from main military and security offices, $500 \mathrm{~m}$ other security offices.

b)Flight Restriction based on the vertical height, flight time

The specified endurance is limited to 15 mins, range within the horizontal distance of $300 \mathrm{~m}$ the $100 \mathrm{~m}$ altitude is maintained.

The Maximum flight above ground level is $200 \mathrm{ft}$ (see details in Table 3)

c)Flight based on the visibility

As per the guideline of (Civil Aviation Authority of Nepal, 2015), the flight was conducted within VLOS because it is not allowed to operate beyond VLOS.

\subsubsection{Regulations that govern Administrative Procedure:}

\section{a) Registration of Platform, UAVs devices}

The UAV used in the case of humanitarian response was brought by DJI. Later on the UAVs were donated to KU for use in academic purposes. The registration requirement of the UAV was not mentioned in Flight Operation Directives 2015. 
At present, the UAV device needs to be registered and should obtain unique identification number (UIN).The procedure for registration is clearly provided. The required documents include identity cards like citizenship of individual/company, purpose of UAVs, specification of devices, VAT and Tax bill (purchased within country), customs clearance certificate (for imported drones). The UIN number is then attached to the UAV.

b)Flight approval (National, Local, local police, land owner)

Flight permission needs to be taken for each flight. The case reveals that the flight was conducted with support of CAAN. Besides, the local partner was involved during the flights. As stated in the Flight Operation Directives 2015, if the weight of the UAV is more than $7 \mathrm{Kg}$ excluding fuel but including any articles must obtain permission of concerned authority, the UAV used in the case is only $1.28 \mathrm{~kg}$. Moreover, the directive speaks about security clearance from the concerned authority is required prior to getting permission from CAAN. The case reveals that permission and cooperation are from the local authority as well.

Documents to be presented to get permission to fly are drone registration certificate, flight details including time, duration, purpose and location map (Google Map), authorization letter from local people/ organization for foreigner/ foreign organization, UAVs pilots' full information consisting of biodata, citizenship copy, valid visa (if foreigner pilot) and commitment letter of UAV pilot mentioning he/she will conduct the flight binding to the legal framework (Ministry of Home Affairs, 2019).

\begin{tabular}{|c|c|c|c|}
\hline $\begin{array}{l}\text { Drone } \\
\text { Catagory }\end{array}$ & Purpose & $\begin{array}{l}\text { Flight Approval } \\
\text { organization }\end{array}$ & Remarks \\
\hline A, B & Academic & $\begin{array}{l}\text { required to inform } \\
\text { local police/ No } \\
\text { permission } \\
\text { required }\end{array}$ & $\begin{array}{l}\text { Within premises } \\
\text { academic } \\
\text { institutions / Max. } \\
200 \mathrm{ft} \text { AGL }\end{array}$ \\
\hline A, B & $\begin{array}{l}\text { Government } \\
\text { activities }\end{array}$ & $\begin{array}{l}\text { required to inform } \\
\text { local police / No } \\
\text { permission } \\
\text { required }\end{array}$ & Max. $200 \mathrm{ft}$ AGL \\
\hline A & $\begin{array}{l}\text { Recreational } \\
\text { /ceremony }\end{array}$ & $\begin{array}{l}\text { required to inform } \\
\text { local police / No } \\
\text { permission } \\
\text { required }\end{array}$ & $\begin{array}{ll}\text { Within } & \text { premises } \\
\text { of } & \text { personal } \\
\text { property } & \text { Max. } 50 \\
\mathrm{ft} \text { AGL/ } & \end{array}$ \\
\hline $\mathrm{A}, \mathrm{B}$ & $\begin{array}{l}\text { Other purposes } \\
\text { like business }\end{array}$ & $\begin{array}{l}\text { District } \\
\text { Administrative } \\
\text { office, } \\
\text { concerned } \\
\text { authority }\end{array}$ & Max. AGL $200 \mathrm{ft}$. \\
\hline C, D & & $\begin{array}{l}\text { Permission } \\
\text { required from } \\
\text { Ministry of Home } \\
\text { Affairs } \\
\text { Ministry of } \\
\text { information and } \\
\text { communication } \\
\text { Other related } \\
\text { Ministry } \\
\text { Coordination with } \\
\text { District Civil } \\
\text { Aviation offices }\end{array}$ & \\
\hline
\end{tabular}

Table 3. Flight Approval

To obtain permission from the concerned offices, it must be assured about the criteria mentioned in section 3.3 .3 are fulfilled. The granted permission to fly UAV cannot be transfer to others people/organizations.

Besides, the frequency in which the UAV flight is operating should not interfere with the frequency of telecommunication, national security, and CAAN.

c) Insurance policy to cover any harm/ damage by fight operation

The case does not reflect any evidence regarding the insurance policy. However, Drone flying Act 2019, regulates the insurance aspect. Basically, only drone of Category C and D should have third-party insurance.

\subsubsection{Human Resource Requirement}

Technical skills/ Qualification of UAVs Pilots:

The specific qualification of the UAV pilot has not been mentioned in the CAAN directives (Civil Aviation Authority of Nepal, 2015). However, the case reveals that the qualified person who was familiar with UAV technological and functional aspects has conducted the flight. Besides mapping activities in Panga, the team has given hand in training to develop capacity in UAV operation. The flight operation directive only mentions about the 'remote pilot' has the responsibility of himself or herself that flight can be safely carried out.

Whereas, the MoHA rules seem to have provided criteria required for UAV Pilots. For instance: age limit of 18 years and over, knowledge of radiofrequency, training on technicality of flight equipment, knowledge regarding take-off/ landing, knowledge of the area where the flight is being carried out. Despite the criteria set for UAVs Pilot, there is no provision of distributing license to the individual as given to the aircraft pilot. Rather, there is a provision of flight permission for a particular purpose valid for maximum three months and there is possibility to extend for three months if there is a valid reason to do so (Ministry of Home Affairs, 2019).

\subsubsection{Ethical constraints:}

\section{Data Protection, privacy, data sharing policy}

The case reveals that the data acquired has been used for research and disaster management purposes. The team printed orthomosaic, analyzed it and presented it to the community. The analog maps, as well as digital maps, were handed over to the CDMC. Figure 3 shows the handling of analog maps. Regarding privacy and ethical constraints of sharing spatial information, the CAAN Directives 2015 has mentioned that "any kind of filming or surveillance activities infringing the personal privacy shall be strictly prohibited". However, the regulations do not spell regarding sharing, storage/ deposition of collected data. 


\section{ANALYSIS AND DISCUSSION ON EXISTING REGULATIONS ON UAVS:}

\author{
a. Applicability of UAVs regulations:
}

The regulations are applicable as per the purposes of use, weight limits, and land-use types. Aligning this with the global study on UAVs regulation studied by Stöcker et al. (2017), the countries like Spain, Azerbaizan, Chile, South Africa also have already developed the regulations in this direction. For instance, Spain has weights limits categorization of $2 / 25 / 150$ $\mathrm{kg}$, Azerbaijan $(20 / 150 \mathrm{~kg})$, Chile $(6 \mathrm{Kg})$, Colombia $(25 \mathrm{~kg})$, South Africa (7/20 kg) (Stöcker et al., 2017).

However, the UAV's regulations in Nepal in terms of applicability, need to formulate in more detail and clear in order to facilitate the implementation as each purpose might have different requirements. The general regulations might not fulfill the requirements to conduct flight for each purpose like academic, research, humanitarian response, recreational and tourism, media.

\section{b. Technical Requirements:}

Regarding the regulations for specific technical requirements, unlike in Chile and Colombia such as material used for blades, autopilot and recovery capabilities, GNSS devices, and other safety equipment like parachutes (Stöcker et al., 2017), the Nepal UAVs regulations does not seem to regulate in these factors. However, it reveals that there is a need to consider to define the specific technical requirements based on the purpose of the flight. Similarly, since the Nepal UAVs regulation allowed the flight within VLOS, there is not defined technical requirements regarding the collision avoidance capabilities. While, if the flight is allowed in EVLOS and BVLOS then the specific technical requirements need to be regulated to avoid severe accidents in the air.

\section{c. Operational Requirements:}

The regulations explicitly mention the restriction zones as "No Fly Zone". Both flight operations directives of CAAN and UAV flight regulations have mentioned. The most prominent examples are no-fly zone near to the airport (air route), $5 \mathrm{~km}$ away from the international border (horizontal distance), Aerial radius from political, cultural, religiously, military and security-sensitive areas, etc. These rules are important to apply in terms of privacy of the people and also for security of sensitive information. The no-fly zone is found to regulate in many countries. In addition, the Netherlands and Japan seem to have made provision of on-line map service to identify no-fly zone (Stöcker et al., 2017).

Despite the restricted rules, the case of humanitarian response seems to overrule the UAV's regulations to some extent. Further, according to Ministry of Home Affairs (2019), the UAV flight is restricted to operate immediately after a disaster. However, there is a provision to allow the flight to the national/ international expert by need assessment of the case by providing special permission. During this special permission period, the flight will be conducted under the surveillance of security officer.
This indicates that the hard rules might not be applicable in all cases. Therefore, the regulations should have provisions to accommodate soft rules depending upon a case by case approach for other purposes as well.

\section{d. Administrative Procedure}

The Nepal UAV regulations seem to clearly regulate as there is detail procedures of the registration process and obtaining flight permission. The requirement of UAVs registration is found in other countries as well for instance: Spain, Azerbaijan, South Africa, Rwanda (Stöcker et al., 2017) and USA (Gheisari et al., 2019). Besides having clear registration process at present, the use of UAVs which was donated for academic purpose is not clear. Since the case of humanitarian response reveals that UAVs are donated for academic purposes. To get those UAVs registered, all the required documents cannot be fulfilled. Similarly, there are almost clear regulations about taking permission but the duration of permission procedure is not clear. Moreover, the existing legal regulations (Ministry of Home Affairs, 2019) have mentioned provision of special permission to make UAV flight during disaster management. The unforeseen time frame to fulfill all the bureaucratic process can be serious hurdles on the effective and efficient response of UAV.

One of the strengths of the Nepal UAVs regulation is third party insurance for the Category $\mathrm{C}$ and $\mathrm{D}$ of the UAV types is must. This regulation is not seen in the study of (Stöcker et al., 2017). The point to be noted is that the study was carried out based on the data of 2014, 2015 and 2016 UAV regulations of various countries.

\section{e. Human Resource Requirement}

Regarding requirement of specific qualification of UAV Pilot, Nepal UAV regulation has described minimum standard norms applicable for general public. Whereas, there is no provision for evaluating the practical skill, aeronautical test, theoretical knowledge of the UAVs pilot and providing one-time license similar to the other vehicles and manned aircraft. The regulations of providing license and certification are found in many countries because pilot skills are one of important part that is associated with complexity and risk regarding flight plan and mission (Stöcker et al., 2017)

\section{f. Ethical Constraints}

The UAVs regulation of Nepal provides alert signals that it is necessary to consider by the UAV pilot to be aware that the flight mission does not hamper privacy of people, organizations, etc. It further mentions, the data captured should share with security department if needed. It seems that data privacy, use, and data sharing policy is still very weak. Although this criterion is not explicitly seen in other countries as well (Stöcker et al., 2017), it is important to think in this line for the effective and efficient application of UAV. 


\section{LIMITATION, RECOMMENDATION AND THE WAY FORWARD}

This study has some methodological limitations because the single case of 2015 has been studied. Although the case studies are combined with other approaches like workshops and literature review, it is recommended to apply multiple variant cases on the UAVs application.

Based on the present study, it is recommended to concerned authority that the legal regulations have some shortcomings though Nepal legal regulations are found to be competent in the global framework. Basically, regulations need to be strengthened like duration of permission grant, clarity on concerned authority, registration of UAVs that are gifted or donated, data sharing and privacy, license, allowable to operate in EVLOS and BVLOS by defining explicit technical requirements, specific technical requirement as per risk categorization. The regulations like a restriction to fly over populated areas might be constrained to use the UAV for the study on urban land use planning.

Therefore, the way forward is to integrate hard laws such as government rules and regulations and also soft laws such as community awareness and industry self-control trends regarding use of UAVs. As it is already experienced that in the case like humanitarian response, a hard law might not be able to provide the effective use of UAVs. To do this, the participatory approach between government, private sector, and civil society groups are required.

\section{ACKNOWLEDGEMENTS (OPTIONAL)}

The acknowledgments go to Ms. Paula Dijkstra, Dr. Eva Maria Unger, Dr. Rohan Bennett for organising the Flight 4 Purpose workshop on behalf of Kadastar. Also the authors acknowledged an anonymous reviewer.

\section{REFERENCES}

Civil Aviation Authority of Nepal. (2015). Flight Operations Directives No. 07. Kathmandu, Nepal.

Dalamagkidis, K. (2015). Classification of uavs. Handbook of unmanned aerial vehicles, 83-91.

Department of Geomatics Engineering. (2019). DGE \& Kadastre International, Netherlands Conducted the Interaction Workshop. Retrieved from http://geom.ku.edu.np/

Desa, H., bin Azizan, M. A., Khadir, M. S. A., Suhaimi, M. S., Ramli, N. Z., \& Hat, Z. (2019). Feasibility Study of UAV Implementation in Route Surveying. Journal of Robotics, Networking and Artificial Life, 6(2), 84-88.

Dijkstra, P., Unger, E. M., \& Bennett, R. (2019). Land Action Report: Land Administration for National Development. Retrieved from Kadaster:
Floreano, D., \& Wood, R. J. (2015). Science, technology and the future of small autonomous drones. Nature, 521(7553), 460-466.

Gheisari, M., \& Esmaeili, B. (2019). Applications and requirements of unmanned aerial systems (UASs) for construction safety. Safety Science, 118, 230-240.

Liu, Z.-T., \& Chen, Y.-Y. (2018). Hover-control method for multirotor unmanned aerial vehicle upcast at any angle to take off, computer program product using the same, and multirotor unmanned aerial vehicle using the same: Google Patents.

Meier, P. (2015). Aerial Robotics in the land of Buddha. Ministry of Home Affairs. (2019). Drone Related Flight Work Plan 2019. Kathmandu

Mulero-Pázmány, M., Stolper, R., Van Essen, L., Negro, J. J., \& Sassen, T. (2014). Remotely piloted aircraft systems as a rhinoceros anti-poaching tool in Africa. PloS one, 9(1), e83873.

Ørngreen, R., \& Levinsen, K. (2017). Workshops as a Research Methodology. Electronic Journal of E-learning, 15(1), 70-81.

PIX4D. (2016). Mapping Nepal: Drones and the future of disaster relief. Retrieved from https://www.pix4d.com/blog/mappingnepal?fbclid=IwAR29dGRIJW8ar9BGh7eRYlsQIR2ksOYSqL QdVbX-T31pnTcha03vVssxplw

Puliti, S., Ørka, H., Gobakken, T., \& Næsset, E. (2015). Inventory of small forest areas using an unmanned aerial system. Remote sensing, 7(8), 9632-9654.

Ramadhani, S. A., Bennett, R., \& Nex, F. (2018). Exploring UAV in Indonesian cadastral boundary data acquisition. Earth science informatics, 11(1), 129-146.

Raparelli, E., \& Bajocco, S. (2019). A bibliometric analysis on the use of unmanned aerial vehicles in agricultural and forestry studies. International Journal of Remote Sensing, 40(24), 9070-9083. doi:10.1080/01431161.2019.1569793

Stöcker, C., Bennett, R., Nex, F., Gerke, M., \& Zevenbergen, J. (2017). Review of the current state of UAV regulations. Remote sensing, 9(5), 459.

Stöcker, C., Koeva, M., Bennett, R., \& Zevenbergen, J. (2019a). Evaluation of UAV-based technology to capture land rights in Kenya: Displaying stakeholder perspectives through interactive gaming. Paper presented at the Proceedings of the 20th Annual World Bank Conference on Land and Poverty.

Stöcker, C., Koeva, M., \& Zevenbergen, J. (2019b). UAV Technology: Opportunities to support the updating process of the Rwandan cadastre. Paper presented at the 10th East Africa Land Administration Network (EALAN) Conference 2019.

Yin, R. K. (2003). Case study research : design and methods (Third edition ed. Vol. 5). Newbury Park etc.: Sage. 